\title{
Accessing Virtual Social Worlds: A Unique Methodology for Research in New Media Spaces
}

\author{
David Zemmels \\ School of Mass Communication, Loyola University New Orleans, \\ 6363 St. Charles Ave., New Orleans, LA, 70118 \\ <zemmels@loyno.edu>
}

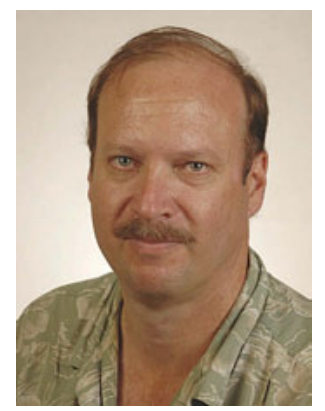

David Zemmels is assistant professor at Loyola University New Orleans and currently teaches digital communication. His primary research interests are at the intersection of media culture, visual communication, aesthetics, and media technology. More narrowly, his research studies issues of media—broadly conceived—and its influence on young people. His interest in both visual aesthetics and digital technologies has defined his career path and research.

David Zemmels. Accessing Virtual Social Worlds: A Unique Methodology for Research in New Media Spaces. Knowledge Organization. 41(3), 230-237. 37 references.

Abstract: Qualitative research into contemporary media engagement is particularly challenged by the complexity and diversity of today's media channels. Further, the very conception of media is rapidly changing: social activities have become closely linked with media engagement. As media saturation in everyday life continues to expand, the study of everyday "practices" in "ordinary people's lives," or habitus, to use Bourdieu's term (1980), constitutes social identity and thus an important object for media research. I offer a reconceptualization of media engagement as a participatory media culture and outline a unique methodological approach developed for the study of this culture in new media spaces. The methodology incorporated use of a laptop to record and analyze the auto-ethnographic reports and actions of a panel of respondents. As an example of an outcome using this methodology, an extensive taxonomy of web sites is outlined, which can be helpful in disaggregating data on new media practices for media research. The methodology could be adapted widely to many disciplines interested in the everyday practices of media engagement.

Received 25 November 2013; Revised 10 February 2014; Accepted 28 February 2014

Keywords: new media, participants, study, practices, research

\subsection{Introduction}

Qualitative research of media interaction, particularly specific everyday practices, is a very challenging prospect because often it is the study of individuals situated in the relationship of time, place, and reference (Lindlof 1990). More to the point, data collection of online new media practices present many new practical challenges for media research. The Internet is without beginnings, centers, or ends, making problematic traditional qualitative research approaches such as conceptualizing the scene and observing social actors. New media here is defined as "a media ecology where more traditional media such as books, television, and radio are intersecting with digital media" (Ito
2010, 10) and the "remediation" (Bolter and Grusin 2000, 5) that inevitably follows the emergence of each new medium whereby older media "jockey for position" in the intertextual media landscape by redefining themselves and their audience.

For a prior study of youth practices in new media spaces (Zemmels 2011), a unique methodology was developed that could benefit media research in many areas of scholarly interest. The methods mitigate many of the challenges to qualitative approaches by providing access to home environments over a protracted period of time, and accounting for the diversity of use in terms of day and time. Using a software package called Morae, a web usability testing software package, reduces the physical 
properties of the direct observation to the seeing eye of a small built-in camera and microphone synced with screen capture information. Also lacking in the literature are clear categorical distinctions between new media web sites based on actual user engagement. As part of this study, a general classification of web sites is presented and is grounded in the data provided by the methodological approach. By disaggregating the media under the general umbrella of new media, more coherent classifications of new media become possible.

\subsection{General literature review}

\subsection{Reconceptualizing media audience research}

The study of media and their influence has evolved significantly since mass audiences were first conceptualized, and new media appears to be accelerating the redefinition of audiences. Early mass media audience research focused on the cognitive effects of media from a reductionist, quantitative positivist perspective (Livingstone 1998). The focus was on content analysis of media texts, with little interest in how meaning is made in mediated experiences. Media was assumed to have great power over audiences (Adorno 1991) with potentially harmful effects of media messages, such as propaganda influences (for example, Lasswell 1927) and promoting violence (for example, Anderson and Bushman 2002).

Beginning in the 1940s, researchers such as Herzog (1941) and Katz (Lazarsfeld and Katz 1955) began to question a direct influence of media. Using quantitative methodologies, viewers came to be understood not as passive "victims" of media and their impact, but rather as active "consumers." The goal was to understand what people do with the media, rather than what the media do to them (Halloran 1970). Qualitative research methodologies were developed to examine how audiences make meaning in mediated experiences. However, the "effects" of media on audiences remained a central concern (Chaffe 1977).

In the 1980s researchers began to develop a more nuanced understanding of the relationship between audience and media; one that is negotiated, whereby audience may confirm, adapt, or reject the influences encoded in media texts (Hall 1980). From this new perspective, media audiences are conceptualized as active participants in mediated communication; they construct meanings from the content they consume. As Anderson and Meyer $(1988,89)$ argued: "Meaning emerges in the interaction among content, context, and communicants." The cultural object (content) is at the center of this interactive process. Meaning for audiences (communicants) is not fixed, but instead relies on the cultural conditions of its reception (context). As contemporary media research methods shift away from textual in- terpretation of media toward contextualization of media practices, understanding the influence of media in everyday life becomes a circular rather than a linear process that should be studied in the context of its reception. As media saturation in everyday life continues to expand, the study of everyday "practices" in "ordinary people's lives" can be particularly informative to researchers. The user's habitus, to use Bourdieu's $(1980,52)$ term for the construction of daily practices, constitutes social identity and thus an appropriate object of study for media research. Further, the term 'audience' no longer adequately describes the media user any longer (Livingstone 1999). At the heart of new media practices are their participatory nature, where socializing takes on the very character of the Internet itself. An important characteristic of new media practices are the constitutive role of the users, in terms of personal voice and sociability (Jenkins 2009). Henry Jenkins (2006) describes this as participatory media culture, which differs sharply from traditional conceptions of audiences as passive media spectatorship.

\subsection{Challenges to new media research}

As the screens available for media consumption have diversified, so too have the consumption practices, making empirical methods of study observation more difficult. With the notion of mass audience culture evolving into participatory media culture, traditional ethnographic approaches are problematic because of the difficulty of entering the scene of actual media engagement. New methods for studying practices of new media engagement are needed (Livingstone 19991; Murphy and Kraidy 2003) because the use of qualitative methods for the study of participants' new media practices “appears to be entering an awkward adolescence" (Lindlof and Taylor 2002, 61). Further, researchers are studying a moving target as the practices seem to evolve and adapt almost as quickly as the technologies (Livingstone 2003). A useful next step in new media research is methodologies that allow investigators to listen to audiences. As Schiappaa and Wesselsa $(2007,15)$ argue, rather than popular media as the object of critical analysis by "academic scholars and popular pundits," audience research needs to recognize the need to listen to audience members in order to understand the interactive process that Anderson and Meyer (1988) proposed.

\subsection{Method}

\subsection{A grounded approach}

The approach and methodology outlined here provided a unique opportunity to directly observe mediated activities 
and the daily practices that surround online socializing, entertainment, and information seeking in an activitybased study of American teens (13-17 years of age) and their material engagement with new media (Zemmels 2011). I took a grounded-theory approach (Glaser and Strauss 1967; Strauss 1987) to capture and analyze the auto-ethnographic reports and actions of the teen respondents. Study participants were asked to orally report what they experience as they experience it. Reports and on-screen activities are recorded by a laptop computer given to the respondents as part of the study.

Originally I asked several research questions, but the following is the one relevant to the results discussed here:

RQ1: What specific patterns and practices are evident as youth (age 13-17) make meaning and socialize in new media environments?

Thus, the methodology was developed to define the specifics of everyday practices, and how they influence, or are influenced by, young peoples' relationships in participatory media culture and grounded in the everyday practices of the study participants.

\subsection{Study procedure}

The study was conducted over a 10 -week period between late May 2010 and mid-July 2010. Eleven young people participated in the study, ranging in age from 13 to 17 . A form of snowball sampling (Heckathorn 1997) was employed; existing study participants provided the basis to nominate and recruit future subjects from acquaintances based on the subject's communication practices. They were asked to select "randomly" (intended colloquially to mean "by chance") two to three people from the list of their Facebook friends as the means of nominating the next round of study participants.

Upon agreeing to the study, each participant was given a laptop computer with software called Morae that records their activities and voice, the Microsoft Internet Explorer (IE) web browser, and other communication and graphic software. The two study laptops were Intel-based computers with built-in camera and microphone. Morae, by TechSmith, is a usability testing and user experience research software package, which requires Microsoft Windows operating system. Morae has three elements, of which two were used: the Recorder and the Manager. The Recorder captures, processes, and stores data from the user experience on the respondent's study laptop computer. Upon the return of the laptop, data were transferred to a desktop office computer with the Manager, which is where the data are coded and analyzed. The specific features of the Manager that facilitated coding are discussed below in the data analysis section. The third element, Observer, monitors a live Recorder session, which may be useful in research, but was not used here.

Working in the background, the Recorder documents key aspects of the user's online experience: the software records video and audio (through the built-in camera and microphone), on-screen activity (screen shots), and keyboard/mouse input. The Morae software provides several options for when to start the recording, and in this study, recording began when the participant launched IE. From that point on, all online activities were recorded and synchronized with the capture of their orally reported thoughts and feelings as they occurred in real-time. Also, all other activities in the range of the camera and microphone were recorded, effectively capturing some aspects of the relationship between offline activities and online practices in the moment of engagement. Recording stopped when IE was closed. In this way, the study laptop computer was both the point of access to online computer mediated spaces and the instrument that recorded the experiences of new media participation and activities in the "natural context of their occurrence, among the actors who would naturally be participating in the interaction, and follows the natural stream of everyday life" (Adler and Adler 2000, 81).

\subsection{Study protocol}

I utilized a protocol analysis methodology wherein participants were asked to orally report what they were experiencing (Ericsson and Simon 1993) so the laptop could capture and document those experiences in real time. Per protocol analysis, participants were asked to "verbalize their thoughts in a manner that does not alter the sequence and content of thoughts mediating the completion of a task and therefore should reflect immediately available information during thinking” (Ericsson 2006, 227). A hybrid form was employed because the goal was not analysis of thinking processes related to specific tasks assigned by a researcher, but of the thinking processes, everyday feelings, and 'thought sequences' of the participants in the moment of their engagement with new media.

Csikszentmihalyi and Kubey (1981) successfully integrated protocol analysis into mass media research. They argued that "methodological and theoretical limitations make it difficult for social scientists to adequately access the impact or value of any form of leisure or medium of communication" (Kubey and Csikszentmihalyi 1990, xii). I drew from their methodological model because "it is designed to provide a picture of the way people feel as they move through everyday life" (Kubey and Csikszentmihalyi 1990, xiii). 


\subsection{Experience sampling}

For analysis I used the experience sampling method (ESM), which is a set of techniques to document human behaviors, thoughts, or feelings as they occur in real-time. Csikszentmihalyi and Larson (1987) coined the term experience sampling method to refer to any assessment of experiences having three characteristics: in natural settings, in real-time, and on repeated occasions. The sample data can include "naïve" accounts of events because validity comes from repetition, not specific responses (Csikszentmihalyi and Larson 1987). Subjects are asked to self-report in response to any number of signals or cues, and in this study, participants were asked to self-report on particular events in naturally occurring new media activities. ESM has the advantage in media research of being less intrusive than other direct observation and data recording techniques that can result in bias from pressures on normal behavior and privacy (Kubey, Larson and Csikszentmihalyi 1996).

Instead of making written notes in journals, as is typical of this method, participants in this study were asked to orally report what they were thinking and feeling, in order to assess their condition in the moment under analysis. This hybrid implementation of ESM is known as image-based experience sampling (Intille, Kukla and Ma 2002) and is appropriate when stopping to report disrupts the flow of users' activity. Verisimilitude was assessed by analyzing the information expressed as verbalized thoughts and comparing that to the on-screen activities, providing evidence that the concurrent verbalization reflected the mediated practices in which they were engaged. Card et al. (Card, Pirolli et al. 2001) successfully applied protocol analysis methodology to Internet research in a task-oriented study under controlled conditions. This project extended the methodology to the relatively chaotic context of everyday lived experience.

\subsection{Data analysis}

In Morae Manager, the investigator sees continuous screen capture of what the participant was seeing and doing and video capture of the participant's face through the camera. At the same time, the investigator listens to recorded audio of both oral reports and any sounds generated by the laptop speakers, which is synced with screen capture video. A multistep coding process differentiated between the use events themselves - coded as cases, episodes, and actions - and the study participants' reports. Initially, the two texts were coded separately because use events were always actions and reports could be related to the actions, but often were not: Some were descriptions of the actions, while others could be talking about the friend they are chatting with, why "kids" like social media, how much they hate it when people do certain things online, and so on. Any interrelation between these two coding processes was accounted for later in the axial coding step of the analysis.

For use event data, the case was the initiation of access to the Internet (opening a web browser), and the unit of analysis was the episode of visitation to a web site. Duration of episodes varied widely, from 15 seconds to 2 hours. Specific actions within an episode were also the object of coding, such as chatting, posting a status update, visiting a photo album, updating personal profile information, adding a Facebook friend, etc. For reportage data, an oral report was the case and thought structure was the unit of analysis. A report was defined as a case if it represented at least one complete verbalized thought that related to the online activities. Reports on other topics unrelated to Internet use, such as relationship with parents or siblings or feelings about school, were coded but not considered a case for analysis. A thought could be structured to relate to a specific online activity, but thought structures could, and often were, a sequence with more than one complete thought. After initial coding, conceptual groups of use event and report codes were organized to make coding more manageable, and then groups were placed into broad categories.

\subsection{Coding using Morae Manager}

The Morae Manager software provided some unique help in coding because the researcher has two interconnected and overlapping means of making notations on the timeline of a recording: tasks and markers. While designed for usability testing, these tools were very useful for demarcating timeline segments within the recorded data and adding research notes to specific reports and actions. The first step in this analysis was to assign a task that described what type of Internet sites the participants were visiting at any moment in the timeline, providing a context for the cases. Tasks are intended by the software designers to label larger sections of recorded data to represent the context in which specific activities occur and then provide a place to make research notes about specifics of the task, which become searchable.

\subsection{Results}

In this study, the tasks feature was used to define and organize the genre or type of web site visited by the study participants. Ito proposed "the notion of genres of participation" (Ito 2010, 15) to differentiate between types of social network sites (SNS) and I expanded that notion to encompass all web sites visited. Ito proposed these 
genres based on the everyday practices of young people but they might reasonably be applied to participants of all ages and across many types of web sites. Two broad categories of genres emerged from episode coding: SNS and non-SNS (Non-social Network Sites).

Table 1 represents a taxonomy that summarizes and defines the genres of the sites visited by participants of this study. Following the tradition of a grounded approach, the websites that constitute a category were derived from the specific practices of the study participants, rather than classifications made by previous research. For example, YouTube is often classified as social media, but participants in this study did not generate or upload content for the site, only passively viewed it.

Three genres of participation in SNS were identified. Ito (2010) specifically differentiated between two types of social network sites: friendship-driven and interest-driven, and study data suggested a third: collaboration-driven. Friendship-driven web sites reflect "the dominant and mainstream practices of youth as they go about their dayto-day negotiations with peers and friends" (15-16). The sites are based on local networks and can be a "primary source of affiliation, friendship, and romantic partners, and their lives mirror this local network" (16). Boyd and Ellison (2007) define SNS more thoroughly as, web-based services that allow individuals to construct a public or semi-public profile within a bounded system, articulate a list of other users with whom they share a connection, and view and traverse their list of connections and those made by others within the system. The nature and nomenclature of these connections may vary from site to site (retrieved from JCMC website on 10/14/2010).

Interest-driven web sites are defined by practices such as 'specialized activities, interests, or niche and marginalized identities' (Ito 2010). Unlike friendship-driven social media sites, participants can access User-Generated Content (UGC) without needing to be accepted as a friend, although access to some content can be limited to a de-

\begin{tabular}{|c|c|c|}
\hline & & able 1: Episode Definitions \\
\hline $\begin{array}{l}\text { Social } \\
\text { Network Sites } \\
\text { (SNS) }\end{array}$ & & $\begin{array}{l}\text { Allow individual to construct a networked public profile, } \\
\text { articulate a list of connections to others, and view and visit } \\
\text { others on that list (boyd and Ellison). Media sites support the } \\
\text { exchange of communication messages and other content } \\
\text { between participants. The site itself is conduit for this } \\
\text { exchange. Participatory practices by users are essential } \\
\text { because they provide much of the content. }\end{array}$ \\
\hline & Friendship-driven & Facebook, MySpace \\
\hline & Interest-driven & blogs, niche sites, Flickr, Twitter, networked gaming, etc. \\
\hline & Collaboration & $\begin{array}{l}\text { e-mail, google docs, wikis, crowd sourcing sites, etc. This } \\
\text { includes Jenkin's "participatory media culture." }\end{array}$ \\
\hline $\begin{array}{l}\text { Non-social } \\
\text { Network Sites } \\
\text { (Non-SNS) }\end{array}$ & & $\begin{array}{l}\text { Address a mass public like broadcast media. Access often } \\
\text { does not require a public profile or membership. Are low- or } \\
\text { non-participatory sites providing access to items and } \\
\text { information, without an exchange as in SNS. Content } \\
\text { generated by site/companies but rarely users. Users consume } \\
\text { content, not exchange/share ideas and content. }\end{array}$ \\
\hline Entertainment & & $\begin{array}{l}\text { Represents the intersection of traditional media, commerce, } \\
\text { and mass media culture in digital media environment. }\end{array}$ \\
\hline & $\begin{array}{l}\text { Games (non- } \\
\text { networked) }\end{array}$ & Online gaming sites \\
\hline & $\begin{array}{l}\text { Trad. Mass Media } \\
\text { online }\end{array}$ & Netflix, Hulu, Film and TV shows on YouTube, etc. \\
\hline & $\begin{array}{l}\text { New Media } \\
\text { "Stations" } \\
\end{array}$ & Pandora, PlayList, original media on YouTube, etc. \\
\hline Commerce & & retail shopping, amazon.com, etc. \\
\hline Info Seeking & & google, bing, ask.com, etc. \\
\hline
\end{tabular}


fined subgroup. Using the SNS definition by Boyd and Ellison (2007), participants have the option to construct a public or semipublic profile within a bounded system, but are not required to connect this profile to offline identities. They may articulate a list of other users with whom they share a connection, but that does not limit the ability to participant or for others within the system to view and traverse the network.

A third genre of SNS participation is proposed in the study: collaboration-driven sites. This genre can be thought of as a subset of interest-driven, but there are some fundamental differences in the affordances and limitation of the site architectures. The focus is on supporting and maintaining "collective intelligence," a term coined by French cybertheorist Pierre Lévy (1997) and used by Jenkins (2006) to define online participatory culture, with the purpose of learning, playing, and communicating with one another in what amounts to a qualitatively new way of living.

Once again referencing boyd and Ellison's SNS definition (2007), participants of collaboration-driven sites construct a public or semipublic profile within a bounded system, but identity in this profile can remain ambiguous. The connection is a shared problem, project, or idea on which participants can collaborate, and collaborators can view and traverse the network freely, but with monitoring by site managers. This genre encompasses communities dedicated to wikis, crowdsourcing sites, and other such collaborative sites that support the construction of and contributions to knowledge. Jenkins (2006) described participants as members of knowledge communities that form around mutual intellectual interests, where no traditional expertise exists, and the pursuit and assessment of knowledge is at once communal and adversarial. Further, Ito's (2010) notion of genres of participation was extended to include genres of non-SNS. These non-participatory types of episodes involved interactive web sites, but the practices in these genres tended to resemble traditional media consumption and social practices such as watching television, shopping, gathering information, etc.

\subsection{Using markers to code groups}

In the Morae software, markers are intended for marking, defining, and notating specific activities in the recording's timeline. Once the episodes were defined as tasks, the next step was to assign a marker for each individual case in the timeline of each session. In this study, initial coding placed markers on actions and reports, which were the basic unit of analysis, but the markers were left 'undefined.' In the second phase of analysis, markers were defined as specific codes as the codebook was developed, with one category being 'Oral Reports,' where the tran- scribed text was kept in the notes section of the marker associated with the verbal report in the timeline. Each marker represented a category of codes from the codebook, and individual codes are placed in the notes for that marker. With Morae's sophisticated search capabilities, finding specific text strings, such as codes and keywords in task and marker notes, was a simple matter.

\subsection{Discussion}

The grounded approach using the Morae software captured key aspects of the user's activities, in real-time, and in the context of their occurrence. Together, the 11 study participants began to provide some definition to the decentralized and fragmented structures of online social practice in networked publics. The taxonomy is an outcome of the process of defining online practices. The relationship between culture and media is closely intertwined with the participatory practices of new media users (Jenkins 2009). Directly observing the specific acts of engagement, and listening to the oral reports, provides a unique opportunity to answer questions about the practices that surround the complex negotiation between multiple selves (online and offline) and the computer structures and operations through which these selves are represented to others.

The Morae Recorder was used as a tool for protocol analysis using ESM and provides an opportunity for researchers to observe a first hand expression of the participants' experiences with new media texts, in the moment of engagement, while mitigating inherent challenges of media audience research. The collected data therefore represent contextualized and situated communicative practices as they are negotiated and enacted, because the data collection instrument becomes a part of the study participants' everyday lives. Because the laptops were portable, data about the participants' experiences were captured in the context of difficult-to-observe private domains like the home and the bedroom. A comparative analysis of both private and public online and offline socializing practices such as peer interactions in school, at coffee shops, and so on, becomes possible, which could help provide insights into media culture as it is enacted in more public domains.

Further, this method serves to help historicize media participation. Critical cultural media research seeks to make visible the taken-for-granted everyday practices of media participation, but there is ultimately little historical record of it (Jensen 1987). As Livingstone (2003, 17, 23) points out, "In their routine daily activities audiences leave no physical record," a record "of people's understandings, interpretations, and critical awareness of media contents." This methodology can be used to mitigate this issue as well. 


\subsection{Limitations of the methodology}

Limitations to the methodology may have had some effect on the potential of the findings toward theory building and future application of these methods: laptopspecific practices and technical issues.

\subsection{Laptop-specific practices}

Participants who already had experience using a laptop regularly to access new media tended to provide more thorough insights into everyday practices in this study. Four of the women regularly used a laptop prior to the study, so were able to substitute the machine and continue the practices they had built around its use. Conversely, others typically engaged in online socializing using their mobile phones, so the activities on the laptop were not really typical for them. For those, one week is probably not enough time to adapt new practices for participants used to mobile phones as the primary point of access to the Internet. For future research with this methodology, researchers should consider giving these participants the laptop for a longer period. The drawbacks of more time are that participants may grow bored or forget to orally report over time, and the researcher may need to occasionally make sure the laptop is recording correctly and collect data from the hard drive as it fills up.

\subsection{Technical issues}

Sessions were lost and often for unknown reasons. Some participants reported that they went online more often than the sessions recorded, but no software or hardware problems could be found upon the laptop's return. There was evidence that some tinkered with the Morae software itself-three managed to change their pseudonyms to their real names - and there were other odd glitches including one 26-hour recording of a blank screen after the participant suddenly closed the laptop and Morae apparently continued to record. Perhaps the biggest technical issue encountered was when two participants downloaded video chat software. This kind of software conflicts with Morae for use of the camera and microphone. Unless a resolution could be found for this conflict, video chat software cannot be allowed. This is unfortunate because video chat software is probably an important aspect of online participation.

\subsection{Conclusion}

The methodology developed for this study was designed to account for the relationship between online and offline practices, communities, and cultures by following the par- ticipants as they moved seamlessly through and between them, and to mitigate many of the barriers to direct observation of everyday practices and accommodates for the diversity of use in terms of day and time. Study participants could talk about their world, their everyday activities, and "about key features and processes of the scene" (Lindlof and Taylor 2002, 176) that may be missed without using the software documentation process.

In a field of study where the object is constantly changing and evolving, this methodology provided a snapshot of the contemporary moment and the media practices that surround an emerging participatory culture. Empirical media research must adapt to new practices, like those outlined in the taxonomy based on respondents' actual usage, which tend to be much more migratory and fragmented than mass media ones. Methodologies for observation and analysis of these various conditions are needed because they may prove to be essential steps in the evolution of new social norms and standards in participatory media culture.

\section{References}

Adorno, Theodor W. 1991. The cultural industry. New York: Routledge.

Adler, Patricia A. and Adler, Peter. 2000. Observational techniques. In Norman K. Denzin and Yvonna S. Lincoln, eds., Handbook of qualitative research. Thousand Oaks, CA: Sage.

Anderson, Craig A. and Bushman, Brad J. 2002. The effects of media violence on society. Science 295: 2377-9.

Anderson, James A. and Timothy P. Meyer. 1988. Mediated communication: a social action perspective. Newbury Park, CA: Sage.

Bolter, J David and Grusin, Richard. 2000. Remediation: understanding new media. Chapel Hill: University of North Carolina Press.

Bourdieu, Pierre. 1980. The logic of practice. Stanford, CA: Stanford University Press.

boyd, danah m. and Ellison, Nicole B. 2007. Social network sites: definition, history, and scholarship. Journal of computer-mediated communication 13: 210-30.

Card, Stuart K., Pirolli, Peter, Wege, Mija Van Der, Morrison, Julie B., Reeder, Robert W., Schraedley, Pamela K. and Boshart, Jenea. 2001. Information scent as a driver of Web behavior graphs: results of a protocol analysis method for Web usability. In CHI '01 Proceedings of the SIGCHI Conference on Human Factors in Computing Systems. Seattle, Washington: Association for Computing Machinery, pp 498-505.

Chaffe, Steven. 1977. Mass media effects: new research perspective. In Daniel Lerner and Lyle Nelson, eds., 
D. Zemmels. Accessing Virtual Social Worlds: A Unique Methodology for Research in New Media Spaces

Communications research: a half century appraisal. Honolulu: University Press of Hawaii.

Csikszentmihalyi, Mihaly and Kubey, Robert. 1981. Television and the rest of life: a systematic comparison of subjective experience. Public opinion quarterly 45: 317-28.

Csikszentmihalyi, Mihaly and Larson, Reed. 1987. Validity and reliability of the experience sampling method. Journal of nervous and mental disease 175: 526-36.

Ericsson, K. Anders. 2006. Protocol analysis and expert thought: concurrent verbalizations of thinking during experts' performance on representative tasks. In K. Anders Ericsson, Neil Charness, Paul J. Feltovich and Robert R. Hoffman, eds., The Cambridge bandbook of expertise and expert performance. Oxford: Cambridge University Press, pp 223-42.

Ericsson, K. Anders and Simon, Herbert A. 1993. Protocol analysis: verbal reports as data. Cambridge, MA: MIT Press.

Glaser, Barney G. and Strauss, Anselm L. 1967. The discovery of grounded theory: strategies for qualitative research. Piscataway, NJ: Aldine Transaction.

Hall, Stuart. 1980. Encoding/decoding. In Stuart Hall, Dorothy Hobson, Andrew Lowe and Paul Willis, eds., Culture, media, language: working papers in cultural studies 1972-79. London: Hutchinson, pp. 128-38.

Halloran, James D. 1970. The effects of television. London: Panther.

Heckathorn, Douglas D. 1997. Respondent-driven sampling: a new approach to the study of hidden populations. Social problems 44: 174-99.

Herzog, Herta. 1941. On borrowed experience: an analysis of listening to daytime sketches. Studies in philosophy and social science 91: 65-95.

Intille, Stephen, Kukla, Charles and Ma, Xiaoyi. 2002. Eliciting user preferences using image-based experience sampling and reflection. In Proceeding CHI EA '02 CHI '02 Extended Abstracts on Human Factors in Computing Systems. Minneapolis, Minnesota: Association for Computing Machinery, pp. 738-9.

Ito, Mizuko. 2010. Hanging out, messing around, and geeking out: kids living and learning with new media. Cambridge, MA: MIT Press.

Jenkins, Henry. 2006. Convergence culture: where old and new media collide. New York: New York University Press.

Jenkins, Henry. 2009. Confronting the challenges of participatory culture. Cambridge, MA: MIT Press.

Jensen, Klaus Bruhn. 1987. Qualitative audience research: toward an integrative approach to reception. Critical studies in mass communication 4: 12-36.
Kubey, Robert William and Csikszentmihalyi, Mihaly. 1990. Television and the quality of life: how viewing shapes everyday experience. Hillsdale, NJ: Lawrence Erlbaum Associates, Inc.

Kubey, Robert William, Larson, Reed and Csikszentmihalyi, Mihaly. 1996. Experience sampling method applications to communication research questions. Journal of communication $46 \mathrm{n} 2:$ 99-120.

Lasswell, Harold D. 1927. Propaganda technique in the World War I. Ann Arbor, MI: The University of Michigan.

Lazarsfeld, Paul Felix and Katz, Elihu. 1955. Personal influence. New York: Free Press.

Lévy, Pierre. 1997. Collective intelligence: mankind's emerging world in cyberspace. Cambridge, MA: Perseus Books.

Lindlof, Thomas R. 1990. When media use can't be observed: Some problems and tactics of collaborative audience research. Journal of communication 40 n4: 8-28.

Lindlof, Thomas R. and Taylor, Bryan C. 2002. Qualitative communication research methods. Thousand Oaks, CA: Sage.

Livingstone, Sonia. 1998. Relationships between media and audiences: prospects for audience reception studies. In Tamar Liebes and James Curran, eds., Media, ritual and identity. London: Routledge, pp. 237-55.

Livingstone, Sonia. 1999. New media, new audiences? New media \& society 1: 59-66.

Livingstone, Sonia. 2003. The changing nature of audiences: from the mass audience to the interactive media user. In Angharad N Valdivia, ed., Companion to media studies. Oxford: Blackwell Publishing.

Murphy, Patrick D. and Kraidy, Marwan M. 2003. International communication, ethnography, and the challenge of globalization. Communcation theory 13: 30423.

Schiappaa, Edward and Wesselsa, Emanuelle. 2007. Listening to audiences: a brief rationale and history of audience research in popular media studies. International journal of listening 21: 14-23.

Strauss, Anselm L. 1987. Qualitative analysis for social scientists. New York: Cambridge University Press.

Zemmels, David R. 2011. Youth and new media: constructing meaning and identity in networked spaces. Ph.D. dissertation. Utah: The University of Utah. Available http://content.lib.utah.edu/utils/get file/collection/etd3/id/347/ filename/434.pdf. 